\title{
Caracterização do concentrado protéico de peixe obtido a partir dos resíduos da filetagem de tilápia do Nilo
}

\section{Characterization of fish protein concentrate obtained from the Nile tilapia filleting residues}

\author{
Marina Cabral Rebouças ${ }^{1 *}$; Maria do Carmo Passos Rodrigues ${ }^{2}$; \\ Ruann Janser Soares de Castro ${ }^{3}$; Janaína Maria Martins Vieira ${ }^{4}$
}

\begin{abstract}
Resumo
Este trabalho teve como objetivos a obtenção de concentrado protéico de peixe a partir da carne mecanicamente separada de tilápia do Nilo através de uma metodologia modificada, bem como realizar caracterização físico-química, microbiológica e sensorial do produto obtido. O concentrado protéico foi obtido a partir da carne mecanicamente separada de tilápia do Nilo, através da modificação de uma metodologia já existente, com alterações nas etapas de desodorização e deslipidificação. A caracterização físico-química da matéria-prima e do produto obtido consistiu das seguintes análises: umidade, lipídios, proteínas, cinzas, atividade de água e o grau de oxidação lipídica. As análises microbiológicas consistiram na determinação de Staphylococcus aureus, Coliformes a $45^{\circ} \mathrm{C}$ e Salmonella sp. Utilizou-se o teste de Escala Hedônica para avaliar a aceitação dos atributos sensoriais de aspecto geral, cor e aroma. A carne mecanicamente separada e o concentrado protéico de peixe obtiveram, respectivamente, os seguintes percentuais com relação à umidade $(77,24$ e 4,85\%), proteína $(17,48$ e 85,16\%), lipídios $(4,46$ e $8,20 \%)$ e cinzas $(1,02$ e $2,45 \%)$. Os atributos aspecto geral e cor obtiveram os seguintes percentuais, respectivamente, 46,67 e $60,0 \%$, na faixa de aceitação da escala. O aroma obteve grande rejeição, alcançando uma frequência de $70,0 \%$. A modificação realizada na metodologia de processamento do concentrando protéico de pescado permitiu a obtenção de um produto com baixo teor de lipídios, além de reduzida umidade e elevado teor protéico, de qualidade microbiológica adequada permitindo a obtenção de um produto que poderá ser utilizado para o enriquecimento protéico de alimentos diversos. Palavras-chave: Aproveitamento, carne mecanicamente separada, deslipidificação, desodorização
\end{abstract}

\begin{abstract}
This study aimed to obtain fish protein concentrate from mechanically deboned Nile tilapia using a modified methodology, as well as perform physical-chemical, microbiological and sensory analysis of the obtained product. The protein concentrate was obtained from mechanically deboned meat of Nile tilapia, by modifying an existing methodology, with changes in deodorizing and lipids removal steps. Chemical and physical-chemical raw material and product consisted of following analysis: moisture, fat, protein, ash, water activity and degree of lipid oxidation by the TBA test. The microbiological analysis consisted in the determination of Staphylococcus aureus, Coliforms at $45^{\circ} \mathrm{C}$ and Salmonella
\end{abstract}

\footnotetext{
${ }^{1}$ Discente do Programa de Pós-Graduação em Ciência e Tecnologia de Alimentos, Doutorado. Universidade Federal do Ceará, UFC, Fortaleza, CE. E-mail: marina_reboucas@hotmail.com

${ }^{2}$ Prof $^{\text {a }}$ do Dept ${ }^{\circ}$ de Tecnologia de Alimentos. UFC, Fortaleza, CE. E-mail: carminha@ufc.br

${ }^{3}$ Discente do Programa de Pós-Graduação em Ciência dos Alimentos, Mestrado. Universidade Estadual de Campinas, UNICAMP, Campinas, SP. E-mail: ruannjanser@hotmail.com

${ }^{4}$ Discente do Programa de Pós-Graduação em Engenharia Química, Doutorado. UFC, Fortaleza, CE. E-mail: nainammv@hotmail. com

* Autor para correspondência
} 
sp. Test of Hedonic Scale assessed the acceptability of sensory attributes of appearance, color and aroma. Mechanically deboned meat and fish protein concentrate obtained, respectively, following values of chemical composition: moisture (77.24 and 4.85\%), protein (17.48 and 85.16\%), lipids (4.46 and $8.20 \%$ ) and ash (1.02 and 2.45\%). Attributes of color and appearance obtained following percentages of acceptance, 46.67 and $60.0 \%$. Aroma had a great rejection, reaching a frequency of $70.0 \%$. The modification made in the methodology for processing of fish protein concentrate allowed to obtain a product with low fat content, reduced moisture, high protein content, and appropriate microbiological quality that enabling to get a product that can be used for enrichment protein of various foods.

Key words: Utilization of byproducts, mechanically deboned meat, lipids removal, deodorizing

\section{Introdução}

Considera-se como resíduo todo material que não é aproveitado durante a sua produção ou consumo devido á limitações tecnológicas ou mercadológicas, que não apresenta valor de uso ou mercado, podendo resultar em danos ao meio ambiente quando não é manejado de forma adequada (NOLASCO, 2000; SUCASAS, 2011). O aproveitamento de resíduos agroindustriais é uma boa forma de reduzir os impactos ambientais e desperdícios causados pelos mesmos, gerando empregos e aumentando o crescimento econômico (REBOUÇAS; CAVALCANTE, 2009). Pode haver em alguns casos a produção de resíduos de cerca de $70 \%$ do peso inicial da matéria-prima na aquicultura, pesca e durante processamento do pescado para elaboração de produtos (OETTERER, 1994; SEIBEL; SOUZA-SOARES, 2003). Neste sentido, a indústria pesqueira ainda possui um grande potencial de recuperação dos resíduos gerados durante o beneficiamento de pescados (PESSATTI, 2001).

Segundo Pessatti (2001), a grande inovação na tecnologia para recuperação dos resíduos de pescados foi o aparecimento de equipamentos capazes de separar o material muscular agregado às espinhas com facilidade, sendo este denominado carne mecanicamente separada (CMS). O concentrado protéico de peixe (CPP) consiste em um subproduto do beneficiamento do pescado que surgiu como uma alternativa para a utilização da CMS.

Os produtos de pescados são alimentos com alto valor nutritivo, excelentes fontes de proteínas, cálcio, ácidos graxos insaturados e vitaminas do complexo B. As proteínas de pescado apresentam elevado valor nutricional, com digestibilidade ao redor de 90\% (KIRSCHNIK, 2007).

O CPP possui em média 75\% de proteínas e surgiu da tentativa de obtenção de um produto ainda mais concentrado em termos de proteína e que atendesse alguns requisitos básicos como: quimicamente estável, baixo custo, pequenos teores de umidade e gordura, desodorizado, fácil estocagem e alta digestibilidade (SOUZA et al., 2010).

É um complemento alimentar de grande importância para suprir as necessidades alimentares da população de forma geral, mas principalmente da população carente que possui baixos níveis de proteína em sua dieta. $\mathrm{O}$ processo de produção de concentrados protéicos de pescado é caracterizado por uma tecnologia extremamente simples, sendo basicamente a deslipidificação do pescado para concentrar sua proteína e posterior desodorização. Em países desenvolvidos a produção de concentrado protéico tem uma grande demanda devido ao menor consumo de energia necessário para a sua produção, armazenamento e transporte se comparado com o pescado congelado (PESSATTI, 2001).

Desta forma, a utilização da CMS para obtenção do CPP apresenta-se como uma boa alternativa de aproveitamento deste subproduto do beneficiamento do pescado, originando um produto rico em proteína que poderá ser utilizado para enriquecimento de uma infinidade de alimentos. Nesse contexto, este trabalho teve como objetivo a obtenção de concentrado protéico de peixe a partir da carne mecanicamente separada de tilápia do Nilo através 
de uma metodologia modificada, bem como realizar caracterização físico-química, microbiológica e sensorial do produto obtido.

\section{Material e Métodos}

\section{Obtenção da CMS de tilápia do Nilo}

Foram utilizados os resíduos da filetagem da tilápia do Nilo (Oreochromis niloticus) para a obtenção da CMS, a qual foi cedida pelo Centro de Pesquisas Ictiológicas Rodolpho Von Ihering (Pentecoste, CE) do Departamento Nacional de Obras Contras a Secas (DNOCS). Os resíduos utilizados foram: carcaças, nadadeiras peitorais e aparas do toalete do filé.

Para recuperação da carne foi utilizada uma máquina despolpadora de pescado, marca High Tech, modelo HT 250. A polpa do pescado foi embalada em sacos plásticos de polietileno com capacidade para 2 quilos e armazenadas a temperatura de aproximadamente $-18{ }^{\circ} \mathrm{C}$ até o momento da sua utilização.

\section{Processo de obtenção do CPP}

O concentrado protéico foi obtido a partir da CMS de tilápia do Nilo sendo o processo para sua obtenção uma adaptação do desenvolvido por Vidal (2007).

A CMS descongelada foi imersa em água potável refrigerada e submetida à agitação durante 15 minutos, seguida de filtração para eliminação do excesso de água. Logo após, realizou-se a desodorização com uma solução de ácido fosfórico $0,002 \%$ onde também efetuou-se agitação durante 15 minutos, sendo o excesso da solução eliminado por filtração e prensagem. O resíduo foi seco em estufa com circulação forçada de ar a temperatura de $72{ }^{\circ} \mathrm{C}$ durante 16 horas. Após seco, o produto foi triturado até a obtenção de um pó de granulometria uniforme. A etapa de deslipidificação foi realizada posteriormente colocando-se o material seco em contato com etanol na proporção de 2:1 (etanol:CPP). O material foi novamente seco em estufa com circulação forçada de ar a temperatura de $60^{\circ} \mathrm{C}$ por 2 horas. Finalmente, o CPP foi acondicionado em embalagem de polietileno biorientado metalizado e selado a vácuo.

A modificação realizada na metodologia de obtenção de CPP a partir da tilápia do Nilo desenvolvida por Vidal (2007) consistiu no aumento da concentração da solução de ácido fosfórico em 0,001\% e na inversão da ordem da deslipidificação, que originalmente era realizada depois da etapa de desodorização e não após a secagem.

Caracterização química e físico-química da CMS e do $C P P$

Para a caracterização da matéria-prima utilizada e do produto obtido realizou-se as seguintes análises segundo metodologia da AOAC (1992): umidade, lipídios, proteínas e cinzas.

A caracterização físico-química consistiu nas análises de atividade de água (Aw) e avaliação da oxidação lipídica através do teste do ácido 2-tiobarbitúrico (TBA). A Aw foi medida com o auxílio do equipamento AquaLab CX-2, da marca Decagon Devices Inc. O teste do TBA foi realizado de acordo com a metodologia descrita por Rahayo, Sofos e Schmidt (1992) e modificada por Facco (2002).

\section{Caracterização microbiológica}

A Agência Nacional de Vigilância Sanitária (ANVISA) estabelece que os microrganismos padrões para avaliação microbiológica de produtos derivados de pescado são: Staphylococcus aureus, Coliformes a $45{ }^{\circ} \mathrm{C}$ e Salmonella sp. (BRASIL, 2001). As determinações foram realizadas de acordo com os métodos estabelecidos pela American Public Health Association(2001). 


\section{Caracterização sensorial}

Utilizou-se o teste da Escala Hedônica estruturada mista de nove pontos $(1=$ "desgostei muitíssimo"; 5 = "nem gostei, nem desgostei"; 9 = "gostei muitíssimo") para avaliar a aceitabilidade dos atributos sensoriais de aspecto geral, cor e aroma do CPP (STONE; SIDEL, 2004). Participaram do teste 30 julgadores não treinados de ambos os sexos e de diferentes faixas etárias. Os resultados foram avaliados através de gráfico em histograma de frequência. Os julgadores foram ainda solicitados a descreverem o(s) aroma(s) percebido(s) e os que obtiveram maior frequência de citação foram elencados em gráfico com os seus respectivos percentuais.

\section{Resultados e Discussão}

Os resultados da caracterização química da CMS e do CPP são apresentados na Tabela 1 . O elevado teor de umidade $(77,24 \%)$ da CMS demonstra a perecibilidade deste produto, tornando necessária a utilização de métodos de conservação eficientes que controlem as possíveis alterações, principalmente às de origem microbiológica.

Tabela 1. Resultados das análises químicas realizadas na carne mecanicamente separada e no concentrado protéico de pescado.

\begin{tabular}{ccc}
\hline & CMS & CPP \\
\hline Umidade (\%) & $77,24 \pm 0,254$ & $4,85 \pm 0,021$ \\
Proteína (\%) & $17,48 \pm 0,048$ & $85,16 \pm 0,481$ \\
Lipídios (\%) & $4,46 \pm 0,117$ & $8,20 \pm 0,015$ \\
Cinzas (\%) & $1,02 \pm 0,00049$ & $2,45 \pm 0,003$ \\
\hline
\end{tabular}

Fonte: Elaboração dos autores.

O teor de $17,48 \%$ de proteína já caracteriza a CMS como uma excelente fonte deste macro nutriente e demonstra a viabilidade de utilização deste subproduto para obtenção de um concentrado protéico, bem como outros produtos alimentícios de alto valor biológico. O teor protéico encontrado deve-se em grande parte as proteínas miofibrilares, mas também as sarcoplasmáticas e estromáticas (KIRSCHNIK, 2007). O resultado obtido neste estudo é maior do que o obtido por Kirschnik e Macedo-Viegas (2009), que obtiveram 15,13\% de proteína em CMS de tilápia do Nilo.

Com relação ao teor lipídico $(4,46 \%)$ o mesmo é relativamente elevado, o que de certa forma constitui um obstáculo na obtenção de CPP, visto que este produto deve possuir baixa concentração de gordura o que aumenta a sua estabilidade com relação a reações oxidativas. $\mathrm{O}$ conteúdo de lipídios no pescado é muito variável, dependendo da espécie, idade, região do corpo, ciclo sexual e alimentação (EYMARD et al., 2005). Em geral, as características químicas encontradas no filé, irão refletir na composição do resíduo (CMS), mas em alguns casos, o percentual lipídico pode ser mais elevado devido à deposição de gordura na região abdominal do peixe, de onde é retirada a maior parte da carne não aproveitada na filetagem (REBOUÇAS et al., 2008). Desta forma, fazemse necessárias etapas de deslipidificação deste material durante o processo de obtenção do concentrado. Leonhardt et al. (2006), corroboram o descrito anteriormente, visto que ao estudarem a composição química de filés de tilápia do Nilo encontraram uma menor concentração de gordura (2,96\%). Já Kirschnik e Macedo-Viegas (2009) ao avaliarem a composição química de CMS de tilápia do Nilo antes e após a lavagem, obtiveram nesta primeira uma concentração de $2,91 \%$ de lipídios, resultado este menor do encontrado nesta pesquisa. A discordância dos valores obtidos neste trabalho com os existentes na literatura são perfeitamente aceitáveis, pois a composição química de uma espécie de peixe pode ser extremamente variável. Diversos fatores de natureza intrínseca, como os genéticos, morfológicos e fisiológicos, bem como os extrínsecos, como a alimentação e o sistema de cultivo e habitat, afetam a composição química dos peixes (OGAWA; MAIA, 1999). 
Com relação ao teor de cinzas $(1,02 \%)$, o mesmo pode variar bastante, de $0,1 \%$ a $3,3 \%$, dependendo de como o peixe é analisado (CONTRERASGUZMÁN, 2002). Neste caso, a inclusão das nadadeiras e peitorais à polpa de pescado contribuem significativamente neste percentual obtido.

Com relação ao CPP podemos verificar que houve uma redução percentual no teor de umidade de aproximadamente $73 \%$ quando comparado ao teor de umidade inicial da CMS. Esta diminuição no teor de água é uma vantagem do ponto de vista de preservação deste produto, principalmente se considerarmos as alterações microbiológicas. A secagem atua preservando o alimento devido à remoção de água, sem a qual os microrganismos não conseguem crescer (JAY, 2005). A Aw encontrada foi de 0,21 , a qual é muito baixa para o crescimento da maioria dos microrganismos. Os resultados das análises microbiológicas (Tabela 2) corroboram o descrito, visto que a contagem dos microrganismos padrões apresentou-se dentro dos limites estabelecidos pela legislação brasileira através da RDC $n^{\circ} 12$ da ANVISA (BRASIL, 2001), o que reflete as condições adequadas de processamento, higiene e manipulação. $\mathrm{O}$ fato de o produto ter sido submetido a temperaturas moderadas por um longo período e ser embalado a vácuo foram cruciais para a manutenção da qualidade microbiológica do produto.

Tabela 2. Resultados das microbiológicas realizadas no concentrado protéico de pescado.

\begin{tabular}{ccc}
\hline $\begin{array}{c}\text { Microrganismo } \\
\text { Coliformes a } 45^{\circ} \mathbf{C} \\
(\mathbf{N M P} / \mathbf{g})\end{array}$ & Amostra & Legislação \\
$\begin{array}{c}\text { Estafilococos coagulase } \\
\text { positiva (UFC/g) } \\
\text { Salmonella } \text { sp }\end{array}$ & $<3$ & $\leq 10^{2}$ \\
\hline
\end{tabular}

Fonte: Elaboração dos autores.

Houve uma grande concentração no teor de proteínas do CPP em relação ao encontrado na CMS. Vale ressaltar, que na CMS o percentual protéico é composto por proteínas miofibrilares e sarcoplasmáticas, onde estas últimas, durante o processo de obtenção do concentrado protéico, são lixiviadas em decorrência dos processos de lavagens. Desta forma o CPP é composto quase que exclusivamente por proteínas miofibrilares e devido ao seu grande percentual este subproduto constituise em uma excelente fonte para suplementação protéica de diversos alimentos.

O baixo teor de lipídios demonstra que os procedimentos realizados para deslipidificação da CMS permitiram uma satisfatória retirada de gordura. Entretanto, para um CPP espera-se que haja um menor percentual de gordura a fim de que o mesmo seja menos susceptível às reações de oxidação lipídica, com consequente formação de compostos "off flavor".

O teste do TBA indicou a presença de 2,27 mg de malonaldeído por quilo de amostra, o que demonstra que antes e durante processamento houve oxidação dos lipídios, o que pode ser justificado pelo fato de que logo após a morte do pescado inicia-se o processo oxidativo que pode ser favorecido pela presença do oxigênio atmosférico, temperatura elevada, desidratação e presença de agentes próoxidantes (STEVANATO et al., 2007). Segundo Ogawa e Maia (1999), com valores acima de $2 \mathrm{mg}$ de malonaldeído/kg o peixe pode apresentar odor e sabor característicos de ranço. No entanto, não existem limites estabelecidos quanto ao grau de oxidação lipídica e presença de odor e sabor de ranço, sendo necessários testes sensoriais que avaliem se os consumidores conseguem detectar a formação destas alterações no produto.

Houve baixa concentração do teor de cinzas, pois grande parte dos minerais é perdida nas etapas de lavagem da CMS (KIRSCHNIK; MACEDOVIEGAS, 2009). Gryschek, Oetterer e Gallo (2003), relataram uma perda de $67 \%$ das cinzas de CMS de tilápia do Nilo após o processo de lavagem.

Com relação à análise sensorial dos atributos de aspecto geral e cor (Gráfico 1), os mesmos obtiveram maior frequência nos valores da escala 
correspondente a faixa de aceitação (valores do 6 ao 9), alcançando os seguintes percentuais, respectivamente, $46,67 \%$ e $60,0 \%$. Apesar da aceitação destes atributos não ter sido elevada, como o CPP deverá ser utilizado como ingrediente para o enriquecimento de produtos, estas características sensoriais não irão influenciar na aparência dos alimentos onde este for adicionado. $\mathrm{O}$ aroma obteve grande rejeição, alcançando uma frequência de $70,0 \%$ na região da escala correspondente aos valores hedônicos de 1 ao 4 . Este elevado índice de rejeição pode ter sido ocasionado pelo odor de peixe que ainda persistiu na amostra depois da etapa de desodorização, visto que aproximadamente $80,0 \%$ dos provadores detectaram este aroma na amostra e cerca de 30,0\% descreveram perceber um odor de camarão (Gráfico 2). Este fato demonstra que mesmo com o aumento da concentração da solução de ácido fosfórico não houve uma desodorização completa do CPP. Cabe destacar, que este aroma de pescado não invalida a utilização do CPP no enriquecimento protéico de alimentos, desde que se consiga disfarçar esta característica no alimento. Outro aroma também citado por parte dos julgadores foi o de leite em pó que está diretamente relacionado com o teor de gordura do CPP. O aroma de álcool possivelmente veio de resíduos do etanol utilizado na etapa de deslipidificação.

Gráfico 1. Frequência dos escores hedônicos para os atributos aspecto geral, cor e aroma

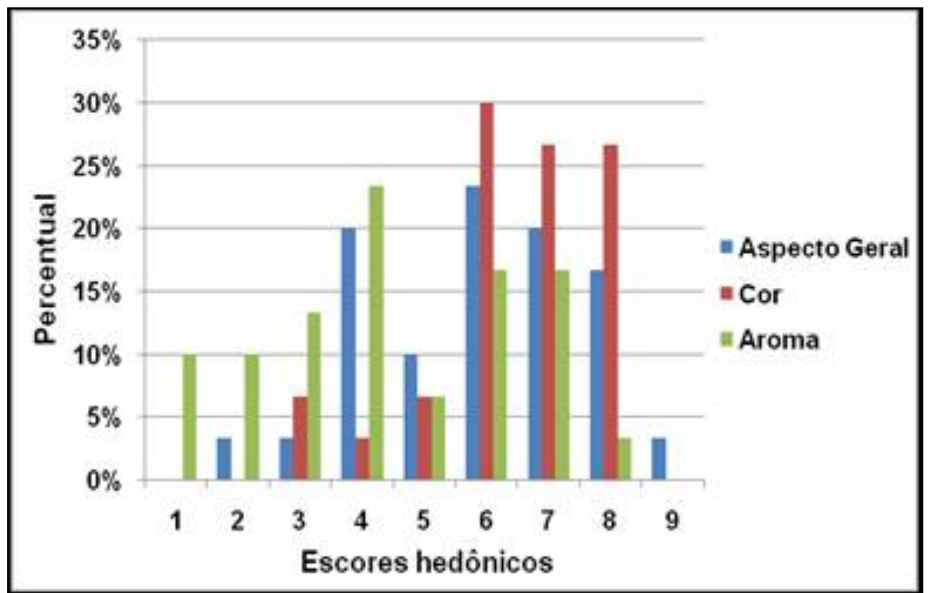

Fonte: Elaboração dos autores.

Gráfico 2. Frequência dos aromas percebidos mais citados pelos julgadores.

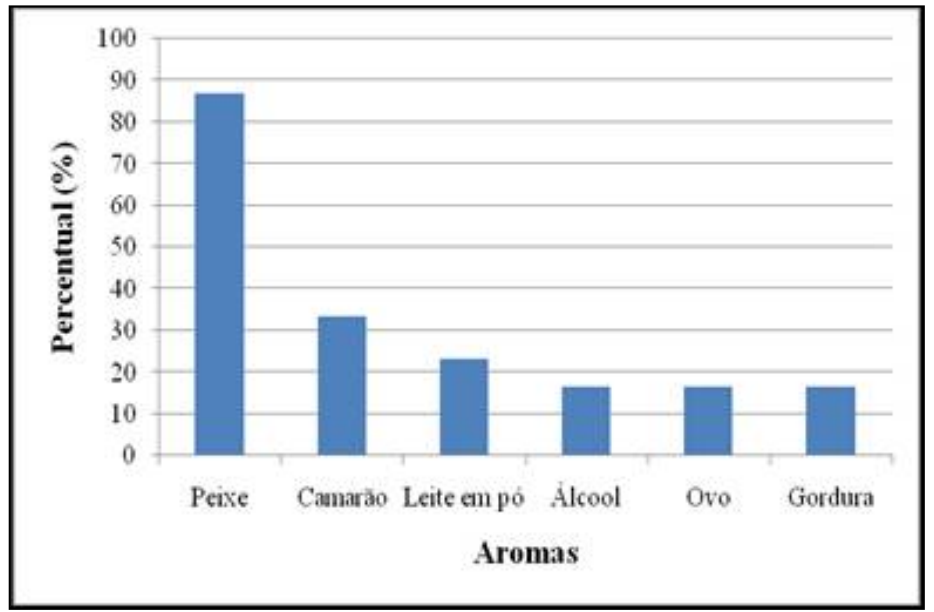

Fonte: Elaboração dos autores. 


\section{Conclusão}

A modificação realizada na etapa de deslipidificação do concentrando protéico de pescado permitiu a obtenção de um produto com baixo teor de lipídios, além de reduzida umidade e elevado teor protéico, de qualidade microbiológica adequada permitindo a obtenção de um produto que poderá ser utilizado para o enriquecimento protéico de alimentos diversos. O processo de desodorização não se mostrou eficiente visto que os provadores ainda conseguiram detectar aroma de peixe no concentrado protéico.

\section{Agradecimentos}

Os autores agradecem a Fundação Núcleo de Tecnologia Industrial (NUTEC) pela realização das análises microbiológicas, ao Centro de Pesquisas Ictiológicas Rodolpho Von Ihering (Pentecoste, CE) do Departamento Nacional de Obras Contras a Secas (DNOCS) por ter cedido a carne mecanicamente separada e ao programa PIBIC/UFC pela concessão das bolsas de pesquisa.

\section{Referências}

AMERICAN PUBLIC HEALTH ASSOCIATION. Compendium of methods for the microbiological examination of foods. 4. ed. Washington, DC, 2001. 1219 p.

ASSOCIATION OF OFFICIAL ANALYTICAL CHEMISTS - AOAC. Official methods of analysis of the association of analytical chemistry. 12. ed. Washington, DC, $1992.1115 \mathrm{p}$.

BRASIL. Ministério da Saúde. Agência Nacional de Vigilância Sanitária. Resolução. RDC n. 12, 20 de dezembro de 2000. Aprova o regulamento técnico sobre os padrões microbiológicos para alimentos. Diário Oficial [da] República Federativa do Brasil, Brasília, 2 de jan. 2001.

CONTRERAS-GUZMÁN, E. S. Bioquímica de pescados e invertebrados. Santiago: CECTA-USACH, 2002, 309 p.

EYMARD, S.; CARCOUËT, E.; ROCHET, M. J.; DUMAY, C.; GENOT, C. Development of lipid oxidation during manufacturing of horse mackerel surimi. Journal of the Science of Food and Agriculture, London, v. 85, n. 10, p. 1750-1756, 2005.

FACCO, E. M. P. Parâmetros de qualidade do charque relacionados ao efeito da suplementação de vitamina Ena dieta de bovinos da raça Nelore em confinamento. 2002. Dissertação (Mestrado em Engenharia de Alimentos) Universidade Estadual de Campinas, Campinas.

GRYSCHEK, S. F. B.; OETTERER, M.; GALLO, C. R. Characterization and frozen storange stability of minced Nile tilapia (Oreochromis niloticus) and red tilapia (Oreochromis spp.). Journal of Aquatic Food Product Techology, Binghamton, v. 12, n. 3, p. 57-69, 2003.

JAY, J. M. Microbiologia de alimentos. 6. ed. Porto Alegre: Artmed, 2005.

KIRSCHNIK, P. G. Avaliação da estabilidade de produtos obtidos de carne mecanicamente separada de tilápia nilótica (Oreochromis niloticus). 2007. Tese (Doutorado em Aqüicultura) - Universidade Estadual Paulista, Jaboticabal.

KIRSCHNIK, P. G.; MACEDO-VIEGAS, E. M. Efeito da lavagem e da adição de aditivos sobre a estabilidade de carne mecanicamente separada de tilápia do Nilo (Oreochromis niloticus) durante a estocagem a $-18^{\circ} \mathrm{C}$. Ciência e Tecnologia de Alimentos, Campinas, v. 29, n. 1, p. 200-206, 2009.

LEONHARDT, J. H.; CAETANO FILHO, M.; FROSSARD, H.; MORENO, A. M. Características morfométricas, rendimento e composição do filé de tilápia do Nilo, Oreochromis niloticus, da linhagem tailandesa, local e do cruzamento de ambas. Semina: Ciências Agrárias, Londrina, v. 27, n. 1, p. 125-132, 2006.

NOLASCO, A. M. Resíduos da colheita e beneficiamento da caixeta - Tabebuia cassinoides (Lam) D.C.: caracterização e perspectivas. 2000. Tese (Doutorado em Ciências) - Escola de Engenharia. Universidade Federal de São Carlos, São Carlos.

OETTERER, M. Produção de silagem a partir da biomassa residual de pescado. Alimentos e Nutrição, São Paulo, v. 5, n. 1, p. 119-134, 1993/1994.

OGAWA, M. Química do pescado. In: OGAWA, M.; MAIA, E. L. (Ed.). Manual de pesca: ciência e tecnologia do pescado. São Paulo: Varela, 1999, cap. 4, p. 29-48.

PESSATTI, M. L. Aproveitamento dos subprodutos do pescado. Meta 11. Relatório final de ações prioritárias ao desenvolvimento da pesca e aqüicultura no Sul do Brasil. Convênio Ministério da Agricultura, Pecuária e Abastecimento (MAPA), Universidade do Vale do Itajaí: MA/SARC, n. 003/2000. 2001. 
RAHAYO, S.; SOFOS, J. N.; SCHMIDT, G. R. Improved speed, specificity, and limit of determination of aqueous acid extraction thiobarbituric acid- $\mathrm{C}_{18}$ method for measuring lipid peroxidation in beef. J. Agric. Food Chem., Washington, v. 40, n. 1, p. 2182-185, 1992.

REBOUÇAS, M. C.; CASTRO, R. J. S.; RODRIGUES, M. C. P.; MESQUITA, M. S. C.; VIEIRA, J. M. M. Caracterização química de carne mecanicamente separada de tilápia-do-Nilo (Oreochromis niloticus) obtida de diferentes sistemas de cultivo. In: ENCONTRO DE INICIAÇÃO À PESQUISA, 14., 2008, Fortaleza. Anais... Fortaleza: Universidade de Fortaleza, 2008.

REBOUÇAS, M. C.; CAVALCANTE, J. M. Avaliação das propriedades funcionais de fibras obtidas a partir de resíduos agroindustriais. In: ENCONTRO DE INICIAÇÃO À PESQUISA, 15., 2009, Fortaleza. Anais... Fortaleza: Universidade de Fortaleza, 2009.

SEIBEL, N. F.; SOUZA-SOARES, L. A. Produção de silagem química com resíduos de pescado marinho. Brazilian Journal of Food Technology, Campinas, v. 6, n. 2, p. 333-337, 2003.

SOUZA, J. F.; BITTENCOUT, N. N.; GOMES, C. S.; OLIVEIRA, J. K. de; SANTOS, R. M. dos.; REIS, I.
A. O.; NUNES, M. L.; NARAIN, N. Desenvolvimento e caracterização físico-química e sensorial de nuggets formulados com concentrado protéico de pescado MARINE BEEF. Scientia Plena, Sergipe, v. 6, n. 3, p. $1-4,2010$.

STEVANATO, F. B.; SOUZA, N. E.; MATSUSHITA, M.; VISENTAINER, J. V. Aproveitamento de resíduos, valor nutricional e avaliação da degradação de pescado. PUBVET, Londrina, v. 1, n. 7, ed. 6, Art. 171, 2007. Disponível em: <http://www.pubvet.com.br/artigos_det. asp? artigo $=171>$. Acesso em: 30 nov. 2011.

SUCASAS, L. F. A. Avaliação do resíduo do processamento de pescado e desenvolvimento de coprodutos visando o incremento da sustentabilidade na cadeia produtiva. 2011. Tese (Doutorado em Ciências) - Universidade de São Paulo, São Paulo.

VIDAL, J. M. A. Utilização de resíduos de filetagem de tilápia-do-Nilo (Oreochromis niloticus) na obtenção de concentrado protéico de peixe: caracterização físico-química e aceitação sensorial. 2007. Dissertação (Mestrado em Tecnologia de Alimentos) - Universidade Federal do Ceará, Fortaleza. 